\title{
HUBUNGAN ADMINISTRATIF DENGAN KELOMPOK TANI DI KECAMATAN LANGOWAN TIMUR KABUPATEN MINAHASA
}

\author{
Debi Rapar \\ Welson M. Wangke \\ Celcius Talumingan
}

\begin{abstract}
This research aims to know the relation of administration with farmer group class in East Langowan Subdistrict of Minahasa Regency. The study was conducted from April to July 2017. The data used were primary data obtained through the administrative examination of the activities and financial administration of each farmer group and direct interviews using questionnaires that were asked to the heads of farmer groups in East Langowan Sub District. Secondary data obtained directly from books, and articles. Data analysis used is descriptive analysis by using table. The Research results showed that the three classes of farmer groups in East Langowan Subdistrict of Minahasa Regency consisting of Beginner Class, Advanced Class and Middle Class, have no relationship with the administration of farmer groups in East Langowan District of Minahasa Regency. The better the administration of a farmer group does not mean that the farmer group should be at the highest grade level.
\end{abstract}

Keywords: relationships, administratives, farmer groups, East Langowan Sub-districts, District Minahasa

\begin{abstract}
ABSTRAK
Penelitian ini bertujuan untuk mengetahui hubungan antara administrasi dan kelas kelompok tani di Kecamatan Langowan Timur Kabupaten Minahasa. Penelitian dilakukan dari bulan April sampai Juli 2017. Data yang digunakan adalah data primer yang diperoleh melalui pemeriksaan administrasi kegiatan dan administrasi keuangan masing-masing kelompok tani dan wawancara langsung dengan menggunakan kuesioner yang diajukan ke kepala kelompok tani di Kecamatan Langowan Timur. Data sekunder diperoleh langsung dari buku, dan artikel. Analisis data yang digunakan adalah analisis deskriptif dengan menggunakan tabel. Hasil penelitian menunjukkan bahwa tiga kelas kelompok tani di Kecamatan Langowan Timur Kabupaten Minahasa yang terdiri dari Kelas Pemula, Kelas Lanjutan dan Kelas Menengah, tidak memiliki hubungan dengan administrasi kelompok tani di Kabupaten Langowan Timur Kabupaten Minahasa. Semakin baik administrasi kelompok tani tidak berarti kelompok tani berada pada tingkat kelas tertinggi.
\end{abstract}

Kata kunci: hubungan, administratif, kelompok tani, Kecamatan Langowan Timur, Kabupaten Minahasa 


\section{PENDAHULUAN}

\section{Latar Belakang}

Sektor pertanian merupakan salah satu sektor terpenting di Indonesia, serta memiliki peranan yang penting dalam menunjang keberhasilan pembangunan yang ada di Indonesia. Dalam hal ini, masyarakat petani memiliki peran yang cukup besar dalam mengelola serta mengatur proses kerja sehingga pengelolaan lahan pertanian dapat berjalan dengan baik. Dimana dalam kelompok tani diperlukan adanya administrasi yang dapat mempermudah kelompok tani untuk melaksanakan tugasnya. Kelompok tani dibentuk berdasarkan surat keputusan dan dimaksudkan sebagai wadah komunikasi antar petani, serta antara petani dengan kelembagaan terkait dalam proses alih teknologi (Wahyuni, 2003). Kelompok tani didefinisikan sebagai kumpulan orang-orang tani atau petani, yang terdiri atas petani dewasa, pria dan wanita, tua dan muda, yang terikat secara informal dalam suatu wilayah kelompok atas dasar keserasian dan kebutuhan bersama serta berada dilingkungan pengaruh dan pimpinan seorang kontak tani. Kelompok tani merupakan organisasi yang dapat dikatakan berfungsi dan ada secara nyata, disamping berfungsi sebagai wahana penyuluhan dan penggerak kegiatan anggotanya. Kecamatan Langowan Timur sebagian besar penduduknya berpenghasilan sebagai petani. Berikut adalah Tabel pembagian dan jumlah kelompok tani yang ada di Kecamatan Langowan Timur.

Tabel 1. Pembagian dan Jumlah Kelompok Tani yang Ada di Kecamatan Langowan Timur.

\begin{tabular}{llc}
\hline No. & \multicolumn{1}{c}{ Nama Desa } & Jumlah Kelompok Tani \\
\hline 1. & Desa Amongena I & 2 \\
2. & Desa Amongena II & 5 \\
3. & Desa Amongena III & 3 \\
4. & Desa Waleure & 3 \\
5. & Desa Sumarayar & 9 \\
6. & Desa Wolaang & 9 \\
7. & Desa Karondoran & 10 \\
8. & Desa Teep & 9 \\
\hline & Total & 50 \\
\hline
\end{tabular}

Sumber: Kantor BP3K Langowan Timur (2017)

Suprayitno (2010), berpendapat bahwa sebuah organisasi Kelompok Tani yang kuat dan maju sudah sepatutnya mempunyai administrasi kelompok yang baik dan benar untuk menunjang semua aktivitas yang dilakukan kelompok tersebut. Perangkat kelengkapan administrasi Kelompok Tani yang semestinya dibuat, digunakan dan dimiliki Kelompok Tani. Administrasi merupakan suatu fenomena masyarakat yang baru, karena baru timbul sebagai suatu cabang daripada ilmu-ilmu sosial, termasuk perkembangannya di Indonesia, dengan membawa prinsip-prinsip yang universal, akan tetapi dalam prakteknya harus disesuaikan dengan situasi dan kondisi Indonesia dengan memperhatikan faktorfaktor yang mempunyai pengaruh terhadap perkembangan ilmu administrasi sebagai suatu disiplin ilmiah yang berdiri sendiri. Kelompok tani yang ada di Kecamatan Langowan Timur dalam perkembangannya mengalami pasang surut. Dibandingkan dengan kelompok tani sekitar, kelompok tani di Kecamatan Langowan Timur belum mengalami kemajuan. Berdasarkan uraian tersebut, maka peneliti tertarik mengambil judul penelitian "Hubungan Administrasi dengan Kelas Kelompok Tani di Kecamatan Langowan Timur Kabupaten Minahasa".

\section{Rumusan Masalah}

Berdasarkan latar belakang yang menjadi masalah dalam penelitian ini yaitu apakah administrasi memiliki hubungan dengan kelas kelompok tani yang ada di Kecamatan Langowan Timur?

\section{Tujuan Penelitian}

Tujuan dalam penelitian ini yakni untuk mengetahui hubungan administrasi dengan kelas kelompok tani yang ada di Kecamatan Langowan Timur Kabupaten Minahasa.

\section{Manfaat Penelitian}

Manfaat dari penelitian ini yaitu untuk memberikan saran serta masukan kepada kelompok tani, tentang administrasi kelompok tani dalam rangka meningkatkan kemajuan kelas kelompok tani di Kecamatan Langowan Timur Kabupaten Minahasa.

\section{METODE PENELITIAN}

\section{Waktu dan Tempat Penelitian}

Penelitian ini dilaksanakan di Kecamatan Langowan Timur Kabupaten Minahasa. Penelitian dilaksanakan selama 2 bulan mulai dari bulan April sampai dengan Juli 2017. 


\section{Metode Pengumpulan Data}

Data yang digunakan dalam penelitian ini berbentuk data primer dan data sekunder. Data primer bersumber dari pemeriksaan administrasi kegiatan dan administrasi keuangan masing-masing kelompok tani dan wawancara langsung dengan menggunakan kuisioner yang ditanyakan kepada ketua-ketua kelompok tani di Kecamatan Langowan Timur. Data sekunder diperoleh langsung dari buku, dan artikel-artikel yang berhubungan langsung dengan penelitian.

\section{Metode Pengambilan Sampel}

Pengambilan sampel menggunakan metode pengambilan secara purposive sampling, dengan jumlah populasi sebanyak 50 kelompok tani yang terdiri dari 37 kelompok tani kelas pemula, 9 kelompok tani kelas lanjut dan 3 kelompok tani kelas madya. Peneliti cenderung memilih informan yang dianggap mengetahui administrasi kegiatan dan administrasi keuangan kelompok tani yang bersangkutan. Responden yang dijadikan sampel dalam penelitian ini adalah masingmasing ketua dari kelompok tani aktif di Kecamatan Langowan Timur sebanyak 15 kelompok tani yang terdiri dari kelas pemula, kelas lanjut dan kelas madya.

\section{Konsep Pengukuran Variabel}

Penentuan penilaian administrasi kelompok tani terhadap kemajuan kelas kelompok tani dapat diukur dengan kategori sebagai berikut:

1. Sangat Baik (SB) diberi skor 5, dan diukur dengan melihat apakah kelengkapan Administrasi Kelompok Tani dalam Kelas Kelompok Tani (Pembukuan diisi lengkap).

2. Baik (B) diberi skor 4, dan diukur dengan melihat apakah kelengkapan Administrasi Kelompok Tani dalam Kelas Kelompok tani (Pembukuan $75 \%$ diisi lengkap).

3. Cukup Baik (CB) diberi skor 3, dan diukur dengan melihat apakah kelengkapan Administrasi Kelompok Tani dalam Kelas Kelompok Tani (Pembukuan 50 \% diisi lengkap).

4. Kurang Baik (KB) diberi skor 2, dan diukur dengan melihat apakah kelengkapan Administrasi Kelompok Tani dalam Kelas
Kelompok Tani (Pembukuan $25 \%$ diisi lengkap).

5. Kurang (SKB) diberi skor 1, dan diukur dengan melihat apakah kelengkapan Administrasi Kelompok Tani dalam Kelas Kelompok Tani (Pembukuan tidak ada).

Berdasarkan pemberian skor tersebut, peneliti menggunakan range skor, sebagai berikut:

1. Range Skor Administrasi Kegiatan

1) Range Skor 0-11 berarti pembukuan dinilai sangat kurang baik.

2) Range Skor 12-22 berarti pembukuan dinilai kurang baik.

3) Range Skor 23-33 berarti pembukuan dinilai cukup baik.

4) Range Skor 34-44 berarti pembukuan dinilai baik.

5) Range Skor 45-55 berarti pembukuan dinilai sangat baik.

2. Range Skor Administrasi Keuangan

1) Range Skor 0-6 berarti pembukuan dinilai sangat kurang baik.

2) Range Skor 7-12 berarti pembukuan dinilai kurang baik.

3) Range Skor 13-18 berarti pembukuan dinilai cukup baik.

4) Range Skor 19-24 berarti pembukuan dinilai baik.

5) Range Skor 25-30 berarti pembukuan dinilai sangat baik.

\section{Administrasi Kelompok Tani}

a. Administrasi kelompok tani dilihat dari 2 bagian pokok yaitu:

1.) Administrasi Kegiatan dalam kelompok tani meliputi:

a) Buku Induk Anggota: Diisi pada saat petani terdaftar sebagai anggota kelompok tani.

b) Buku Kegiatan Kelompok: Diisi catatan dalam rapat.

c) Buku Tamu: Yaitu mengisi daftar kedatangan tamu.

d) Buku Notulen Rapat: Dilakukan saat ada kegiatan yang dibuat.

e) Buku Produktifitas dan Hasil Produksi: Diisi tentang produksi dan produktifitasusaha tani anggota.

f) Buku Agenda Surat Masuk dan Surat Keluar: 
Untuk mencatat surat yang diterima oleh kelompok, juga mencatat surat yang dikirim untuk siapa beserta nomor surat.

g) Buku Ekspedisi:

Diisi pada saat pengiriman surat kepada pihak lain.

h) Buku Kepemilikan Sarana dan Prasarana Kelompok:

Diisi dokumen anggota berisi jenis-jenis sarana dan prasarana pertanian seperti alat-alat dan mesin pertanian yang dimiliki anggota kelompok tani.

i) Buku Luas Lahan Garapan:

Dokumen tertulis yang berisi tentang luas areal lahan garapan anggota kelompok berupa lahan sawah, pekarangan, tegalan, kebun serta jenis-jenis usahatani yang dijalankan para anggota.

j) Buku Pengurus:

Berisi tentang biodata setiap petani yang menjadi pengurus kelompok.

k) Buku Daftar Hadir:

Dokumen yang berisi kehadiran petani yang menjadi anggota kelompok dan setiap kali kelompok mengadakan kegiatan.

2.) Administrasi keuangan dalam kelompok tani meliputi:

a) Buku Kas:

Diisi segala kegiatan yang dilaksanakan oleh kelompok yang menyangkut pengeluaran dan pemasukan keuangan kelompok.

b) Buku Iuran Anggota:

Buku yang mencatat tentang masuknya iuran dalam bentuk uang tunai maupun natura ke dalam kas kelompok.

c) Buku Tabungan Anggota:

Buku yang mencatat tentang masuknya tabungan dalam bentuk uang tunai maupun natura ke dalam kas kelompok.

d) Buku Inventaris:

Dokumen tertulis yang berisi tentang jenis barang, sarana dan prasarana pertanian seperti alat-alat dan mesin pertanian yang dimiliki kelompok baik yang berasal dari pembelian yang dilakukan kelompok tani maupun dari bantuan pemerintah.

e) Buku Penjualan:

Mencatat tentang segala kegiatan penjualan hasil produksi usahatani yang dihasilkan kelompok tani yang dilaksanakan oleh anggota kelompok.

f) Buku Pembelian:

Mencatat tentang segala kegiatan pengeluaran uang yang dipergunakan untuk membeli barang berupa alat dan mesin pertanian serta bahan baku usahatani berupa sarana produksi pertanian seperti pupuk, pestisida.

\section{Kelas Kelompok Tani}

Kelas kelompok tani dalam penelitian ini diukur berdasarkan kelas kelompok tani. Adapun pembagian kelas kelompok tani adalah sebagai berikut:

a. Kelas Madya terdiri dari dua kelompok tani antara lain, Sehati dan Ranombolai.

b. Kelas Lanjut terdiri dari empat kelompok tani antara lain, Hamparan, Reirem, Impit dan Sejahtera.

c. Kelas Pemula terdiri dari sembilan kelompok tani antara lain, Imanuel, Tabur Tuai, Nazareth, Karya Nyata, Sumaru Endo, Looren, Waranei, Taas dan Mamang Tawangan.

\section{Metode Analisis Data}

Analisis Data yang digunakan dalam penelitian ini yaitu menggunakan analisis deskriptif dengan menggunakan tabel. Metode dasar yang dipakai dalam penelitian ini metode deskriptif, yaitu metode yang memusatkan perhatiannya pada pemecahan masalah, data yang dikumpulkan disusun, dianalisis, dan disimpulkan.

\section{HASIL DAN PEMBAHASAN}

\section{Deskripsi Lokasi Penelitian Keadaan Geografis}

Dilihat dari letak geografis maka wilayah Kecamatan Langowan Timur berada pada posisi $1,06^{\ominus}-125,01^{\theta}$, dengan iklim sejuk, temperatur udara $22^{\theta}-29^{\theta} \mathrm{C}$ dengan batas-batas wilayah sebagai berikut:

a. Sebelah Utara berbatasan dengan Kecamatan Langowan Utara

b. Sebelah Selatan berbatasan dengan Kecamatan Langowan Timur/Laut Maluku

c. Sebelah Timur berbatasan dengan Kecamatan Kakas

d. Sebelah Barat berbatasan dengan Kecamatan Langowan Barat 
Jarak hubungan transportasi dari pusat kecamatan ke pusat kabupaten $\pm 20 \mathrm{~km}$ dan jarak ke Ibukota Provinsi $\pm 65 \mathrm{Km}$.

\section{Keadaan Lahan dan Iklim}

Wilayah Kecamatan Langowan Timur meliputi 8 (delapan) desa dengan 46 jaga, dengan total luas wilayah $\pm 1,098$ ha. Dari total luas wilayah ini 662 ha merupakan wilayah persawahan, 198 ha kebun atau tegalan, 209 ha pekarangan. Wilayah persawahan yang terbesar di Kecamatan Langowan Timur adalah sawah irigasi setengah teknis, dan sebagian kecil adalah sawah tadah hujan. Secara umum keadaan topografi wilayah di Kecamatan Langowan Timur adalah landai dan sedikit berbukit. Kemiringan tanah berbukit sampai berkisar 10 persen dari luas wilayah yang berada di Desa Wolaang, Sumarayar, Teep, Waleure yang ditanami tanaman perkebunan dan kehutanan serta sebagian kecil ditanami tanaman pangan seperti jagung. Sedangkan 90 persen dari luas wilayah mempunyai kemiringan lahan landai dengan kemiringan $0-15$ persen yang banyak ditanami tanaman musiman yaitu padi sawah, jagung dan hortikultura lainnya yaitu di Desa Karondoran, Amongena I, Amongena II, Amongena III, Teep, Wolaang, Waleure dan Sumarayar. Ketinggian permukaan daratan dilihat dari permukaan laut berkisar antara $650-700 \mathrm{dpl}$. Jenis tanah yang ada disebagian wilayah ini adalah lempung berpasir. Curah hujan rata-rata pertahun adalah $183,87 \mathrm{~mm}$, curah hujan tertinggi 10 tahun terakhir berada pada bulan Mei dan Juni sedangkan bulan kering berada pada bulan Agustus dan September dengan curah hujan dibawah $100 \mathrm{~mm}$.

\section{Karakteristik Kelompok Tani}

Kelompok tani pada dasarnya merupakan kelembagaan petani di pedesaan yang saling mengenal akrab dan saling percaya antara anggota kelompok tani, mempunyai pandangan dan kepentingan serta tujuan yang sama dalam berusahatani. Kerjasama antara pengurus dengan anggota, anggota dengan penyuluh sangat berpengaruh bagi perkembangan usahatani dalam kelompok. Tabel 2 menunjukkan karakteristik kelompok tani yang menjadi responden di Kecamatan Langowan Timur dapat dilihat pada Tabel 2.
Tabel 2. Karakteristik Kelompok Tani di Kecamatan Langowan

\begin{tabular}{|c|c|c|c|c|c|}
\hline \multirow[t]{2}{*}{ No } & \multirow{2}{*}{$\begin{array}{c}\text { Nama } \\
\text { Kelompok } \\
\text { Tani } \\
\end{array}$} & \multicolumn{4}{|c|}{ Karakteristik Kelompok Tani } \\
\hline & & Lokasi & $\begin{array}{c}\text { Tahun } \\
\text { Terbentuk }\end{array}$ & $\begin{array}{c}\text { Jumlah } \\
\text { Anggota }\end{array}$ & Kelas \\
\hline 1 & Imanuel & Amongena I & 2013 & 20 & Pemula \\
\hline 2 & Nazareth & Amongena II & 2013 & 21 & Pemula \\
\hline 3 & Taas & $\begin{array}{c}\text { Amongena } \\
\text { III }\end{array}$ & 2013 & 21 & Pemula \\
\hline 4 & Karya Nyata & $\begin{array}{l}\text { Amongena } \\
\text { III }\end{array}$ & 2013 & 20 & Pemula \\
\hline 5 & Sehati & Wolaang & 1978 & 20 & Madya \\
\hline 6 & Sejahtera & Wolaang & 1987 & 20 & Lanjut \\
\hline 7 & Hamparan & Karondoran & 2008 & 10 & Lanjut \\
\hline 8 & Ranombolai & Karondoran & 2013 & 20 & Madya \\
\hline 9 & Sumaru Endo & Karondoran & 2014 & 20 & Pemula \\
\hline 10 & Waraney & Waleure & 2008 & 15 & Pemula \\
\hline 11 & Looren & Teep & 2013 & 20 & Pemula \\
\hline 12 & $\begin{array}{l}\text { Mamang } \\
\text { Tawangan }\end{array}$ & Wolaang & 2013 & 25 & Pemula \\
\hline 13 & Tabur Tuai & Amongena II & 2007 & 20 & Pemula \\
\hline 14 & Impit & Amongena II & 2013 & 20 & Lanjut \\
\hline 15 & Reirem & Sumarayar & 2014 & 20 & Lanjut \\
\hline & Total & & & 297 & \\
\hline
\end{tabular}

Sumber: Data Primer (2017)

Kelompok tani di Kecamatan Langowan Timur dominan terbentuk pada tahun 2013. Anggota kelompok tani terbanyak sebesar 25 orang dimiliki oleh kelompok tani Mamang Tawangan yang berlokasi di Desa Wolaang. Kelas kelompok tani yang ada di Kecamatan Langowan Timur didominasi oleh Kelas Pemula.

\section{Karakteristik Responden}

\section{Umur Responden}

Tingkat umur mempengaruhi kemampuan seseorang dalam melakukan aktivitas maupun konsep berpikir khususnya tiap anggota kelompok tani. Anggota kelompok tani yang memiliki umur muda tentunya memiliki kondisi fisik yang lebih kuat, keinginan untuk mencoba hal baru, serta memiliki daya berpikir yang kreatif. Selain itu anggota kelompok tani yang berumur tua cenderung untuk lebih menjaga kesehatannya. Jumlah responden menurut tingkat umur dapat dilihat pada Tabel 3.

Tabel 3. Jumlah Responden Menurut Tingkat Umur

\begin{tabular}{lccc}
\hline No & Tingkat Umur & Jumlah Responden & Persentase \\
\hline 1 & $39-44$ & 2 & 13,33 \\
2 & $45-50$ & 2 & 13,33 \\
3 & $51-56$ & 6 & 40 \\
4 & $57-62$ & 3 & 20 \\
5 & $>62$ & 2 & 13,33 \\
\hline \multicolumn{4}{r}{ Sumber } \\
\hline
\end{tabular}

Sumber: Data Primer (2017)

Kelompok tani di Kecamatan Langowan Timur didominasi oleh responden dengan umur antara 51-56 tahun sebesar 40 persen, selanjutnya responden dengan umur antara 57-62 tahun 
sebesar 20 persen dan responden dengan umur 3944 tahun, 45-49 tahun dan 62 tahun keatas sebesar 13,33 persen.

\section{Pendidikan Responden}

Tingkah laku individu atau seseorang sangat dipengaruhi oleh pendidikan yang telah dicapai. Begitu juga pada anggota kelompok tani, tingkat pendidikan dan pengalaman sangat mempengaruhi cara berpikir. Jumlah responden menurut tingkat.

\begin{tabular}{lccc}
\multicolumn{4}{l}{ Tabel 4. Jumlah Responden Menurut Tingkat Pendidikan } \\
\hline No & Tingkat Pendidikan & Jumlah Responden & Persentase \\
\hline 1 & SD & 4 & 26,67 \\
2 & SMP & 4 & 26,67 \\
3 & SLTA & 6 & 40 \\
4 & S1 & 1 & 6,66 \\
\hline & Total & 15 & 100 \\
\hline
\end{tabular}

Sumber: Data Primer (2017)

Tabel 4 menunjukkan bahwa, kelompok tani di Kecamatan Langowan Timur didominasi oleh responden dengan tingkat pendidikan SLTA sebesar 40 persen, selanjutnya diikuti SD dan SMP 26,67 persen, dan yang terakhir S1 sebesar 6,66 persen. Banyaknya anggota kelompok tani lulusan SLTA dikarenakan sebagian besar penduduknya berpendapatan rendah, sehingga tidak dapat melanjutkan pendidikan ke perguruan tinggi.

\section{Hubungan Administrasi Kelompok Tani dengan Kelas Kelompok Tani}

\section{Penilaian Pembukuan Kelompok Tani Kelas Pemula}

Pemeriksaan pembukuan administrasi kelompok tani kelas pemula. Tabel 5 menunjukkan bahwa kelompok tani di Kelas Pemula memiliki pembukuan administrasi kegiatan dan administrasi keuangan yang dominan dinilai kurang baik. Hal ini dikarenakan ada pembukuan yang tidak diisi lengkap. Pembukuan administrasi kegiatan yang tidak diisi lengkap diantaranya adalah buku induk anggota, buku kegiatan kelompok, buku tamu, buku notulen rapat buku kepemilikkan sarana dan/prasarana anggota, buku pengurus dan buku daftar hadir. Sedangkan pembukuan administrasi keuangan yang tidak diisi lengkap diantaranya adalah, buku iuran anggota, buku tabungan anggota, buku inventaris, buku penjualan dan buku pembelian. Maka dapat dijelaskan bahwa administrasi tidak memiliki hubungan dengan kelas kelompok tani pemula di Kecamatan Langowan Timur.

Tabel 5. Penilaian Pembukuan Kelompok Tani Kelas Pemula

\begin{tabular}{|c|c|c|c|c|c|}
\hline No & $\begin{array}{c}\text { Kelas } \\
\text { Kelompok } \\
\text { Tani } \\
\text { (Pemula) } \\
\end{array}$ & $\begin{array}{c}\text { Skor } \\
\text { Administ } \\
\text { rasi } \\
\text { Kegiatan }\end{array}$ & $\begin{array}{c}\text { Pemeriksaan } \\
\text { Administrasi } \\
\text { Kegiatan }\end{array}$ & $\begin{array}{c}\text { Skor } \\
\text { Administra } \\
\text { si } \\
\text { Keuangan } \\
\end{array}$ & $\begin{array}{c}\text { Pemeriksaan } \\
\text { Administrasi } \\
\text { Keuangan }\end{array}$ \\
\hline 1 & Imanuel & 13 & Kurang baik & 7 & Kurang baik \\
\hline 2 & Tabur Tuai & 20 & Kurang baik & 8 & Kurang baik \\
\hline 3 & Nazareth & 15 & Kurang baik & 6 & $\begin{array}{c}\text { Sangat kurang } \\
\text { baik }\end{array}$ \\
\hline 4 & $\begin{array}{l}\text { Karya } \\
\text { Nyata }\end{array}$ & 16 & Kurang baik & 6 & $\begin{array}{c}\text { Sangat kurang } \\
\text { baik }\end{array}$ \\
\hline 5 & $\begin{array}{l}\text { Sumaru } \\
\text { Endo }\end{array}$ & 25 & Cukup baik & 8 & Kurang baik \\
\hline 6 & Looren & 15 & Kurang baik & 8 & Kurang baik \\
\hline 7 & Waraney & 15 & Kurang baik & 6 & $\begin{array}{c}\text { Sangat kurang } \\
\text { baik }\end{array}$ \\
\hline 8 & Taas & 17 & Kurang baik & 7 & $\begin{array}{c}\text { Sangat kurang } \\
\text { baik }\end{array}$ \\
\hline 9 & $\begin{array}{c}\text { Mamang } \\
\text { Tawangan }\end{array}$ & 18 & Kurang baik & 8 & Kurang baik \\
\hline
\end{tabular}

\section{Penilaian Pembukuan Kelompok Tani Kelas Lanjut}

Pemeriksaan pembukuan administrasi kelompok tani Kelas Lanjut dapat dilihat pada Tabel 6.

Tabel 6. Penilaian Pembukuan Kelompok Tani Kelas Lanjut

\begin{tabular}{lccccc}
\hline No & $\begin{array}{c}\text { Kelas } \\
\text { Kelompok } \\
\text { Tani } \\
\text { (Lanjut) }\end{array}$ & $\begin{array}{c}\text { Skor } \\
\text { Administ } \\
\text { rasi } \\
\text { Kegiatan }\end{array}$ & $\begin{array}{c}\text { Pemeriksaan } \\
\text { Administrasi } \\
\text { Kegiatan }\end{array}$ & $\begin{array}{c}\text { Skor } \\
\text { Administra } \\
\text { si } \\
\text { Keuangan }\end{array}$ & $\begin{array}{c}\text { Pemeriksaan } \\
\text { Administrasi } \\
\text { Keuangan }\end{array}$ \\
\hline 1 & Hamparan & 21 & Kurang baik & 11 & Kurang baik \\
2 & Reirem & 23 & Cukup baik & 10 & Kurang baik \\
3 & Impit & 21 & Kurang baik & 7 & Kurang baik \\
4 & Sejahtera & 18 & Kurang baik & 9 & Kurang baik \\
\hline \multicolumn{5}{l}{ Sumber: Data Primer (2017) }
\end{tabular}

Berdasarkan Tabel 6 dapat dilihat bahwa, kelompok tani di Kelas Lanjut memiliki pembukuan administrasi kegiatan yang dominan dinilai kurang baik dan semua pembukuan administrasi keuangan kelompok tani lanjut dinilai kurang baik. Hal ini dikarenakan ada pembukuan administrasi kegiatan yang tidak diisi lengkap dan semua pembukuan administrasi keuangan yang tidak diisi lengkap. Pembukuan administrasi kegiatan yang tidak diisi lengkap diantaranya adalah buku kegiatan kelompok, buku notulen rapat, buku produktifitas dan hasil produksi, buku agenda surat masuk dan surat keluar, buku ekspedisi, buku daftar hadir. 


\begin{tabular}{lccccc}
\multicolumn{2}{l}{ Tabel 7. Penilaian Pembukuan Kelompok Tani Kelas Madya } \\
\hline No & $\begin{array}{c}\text { Skor } \\
\text { Kelas Kelompok Tani } \\
\text { (Madya) }\end{array}$ & $\begin{array}{c}\text { Administrasi } \\
\text { Kegiatan }\end{array}$ & $\begin{array}{c}\text { Pemeriksaan } \\
\text { Administrasi Kegiatan }\end{array}$ & $\begin{array}{c}\text { Administrasi } \\
\text { Keuangan }\end{array}$ & $\begin{array}{c}\text { Pemeriksaan } \\
\text { Administrasi Keuangan }\end{array}$ \\
\hline 1 & Sehati & 21 & Kurang baik & 8 & Kurang baik \\
2 & Ranombolai & 17 & Kurang baik & 10 & Kurang baik \\
\hline Sumber: Data Primer (2017) & & &
\end{tabular}

Sedangkan pembukuan administrasi keuangan yang tidak diisi lengkap diantaranya adalah buku tabungan anggota, buku inventaris, buku penjualan dan buku pembelian. Maka dapat dikatakan bahwa tidak ada hubungan antara administrasi kelompok tani dengan kelas kelompok tani.

\section{Penilaian Pembukuan Kelompok Tani Kelas Madya}

Pemeriksaan pembukuan administrasi kelompok tani Kelas Madya dapat dilihat pada Tabel 7. Tabel 7 menunjukan bahwa, kelompok tani di Kelas Madya memiliki pembukuan admnistrasi kegiatan dan administrasi keuangan yang dinilai kurang baik. Hal ini dikarenakan semua pembukuan administrasi kegiatan dan administrasi keuangan yang tidak diisi lengkap. Pembukuan administrasi kegiatan yang tidak diisi lengkap diantaranya adalah buku induk anggota, buku produktifitas dan hasil produksi, buku agenda surat masuk dan surat keluar, buku ekspedisi, buku kepemilikan sarana/prasarana anggota, buku daftar hadir. Sedangkan pembukuan administrasi keuangan yang tidak diisi lengkap diantaranya adalah buku iuran anggota, buku tabungan anggota, buku inventaris, buku penjualan dan buku pembelian. Maka dapat dikatakan bahwa tidak ada hubungan antara administrasi dengan kelas kelompok tani. Dimana kelas kelompok tani madya merupakan kelas yang paling tinggi dibandingkan dengan kelas pemula dan kelas lanjut. Sehingga tidak berarti kelompok tani yang berada pada kelas madya memiliki pembukuan yang dikatakan baik.

\section{KESIMPULAN DAN SARAN}

\section{Kesimpulan}

Berdasarkan hasil penelitian dan pembahasan, maka disimpulan bahwa: administrasi kegiatan (1)Kelas pemula. Kelompok tani di kelas pemula memiliki pembukuan administrasi kegiatan yang dominan dinilai kurang baik. Hal ini dikarenakan ada pembukuan yang tidak diisi lengkap. (2) Kelas lanjut. Kelompok tani di kelas lanjut memiliki pembukuan administrasi kegiatan yang dominan dinilai kurang baik. Hal ini dikarenakan ada pembukuan administrasi kegiatan yang tidak diisi lengkap. (3)Kelas madya. Kelompok tani di kelas madya memiliki pembukuan admnistrasi kegiatan yang dinilai kurang baik. Hal ini dikarenakan ada pembukuan administrasi kegiatan yang tidak diisi lengkap. a. Administrasi keuangan. Kelas Pemula. Kelompok tani di Kelas Pemula memiliki pembukuan administrasi keuangan yang dominan dinilai kurang baik. Hal ini dikarenakan ada pembukuan administrasi keuangan yang tidak diisi lengkap. Kelas Lanjut. Kelompok tani di Kelas Lanjut memiliki semua pembukuan administrasi keuangan yang dinilai kurang baik. Hal ini dikarenakan semua pembukuan administrasi keuangan tidak diisi lengkap. Kelas Madya. Kelompok tani di Kelas Madya memiliki pembukuan administrasi keuangan yang dinilai kurang baik. Hal ini dikarenakan semua administrasi keuangan tidak diisi lengkap. Berdasarkan dari ketiga kelas kelompok tani di Kecamatan Langowan Timur Kabupaten Minahasa yang terdiri dari Kelas Pemula, Kelas Lanjut dan Kelas Madya, dapat dikatakan bahwa administrasi dengan kelas kelompok tani ini tidak memiliki hubungan. Semakin baik administrasi dari suatu kelompok tani tidak berarti kelompok tani harus berada pada tingkat kelas yang paling tinggi.

\section{Saran}

Berdasarkan kesimpulan dari hasil penelitian, maka diharapkan agar pihak kelompok tani lebih memperhatikan dan melengkapi administrasi kegiatan dan administrasi keuangannya dan bagi pemerintah agar lebih memperhatikan kesejahteraan kelompok tani di Kecamatan Langowan Timur dengan memberikan bantuan dana untuk melengkapi administrasi kelompok tani yang 
masih dikatakan kurang baik. Diharapkan pembinaan dalam penyempurnaan administrasi kelompok tani di Kecamatan Langowan Timur Kabupaten Minahasa.

\section{DAFTAR PUSTAKA}

Anwarudin, O. 2009. Pengembagan Kelembagaan, Partisipasi Dan Kemandirian Kelompok Tani Dalam Usaha Agribisnis Perdesaan Di Kecamatan Banjaran, Kabupaten Majalengka Barat. Universitas Sebelas Maret Sukarta.

Astuti, A.N. 2010. Analisis Efektifitas Kelompok Tani Di Kecamatan Gatak Kabupaten Sukoharjo. Universitas Sebelas Maret Surakarta.

Departemen Pertanian, 2007. Pedoman Penumbuhan dan Pengembangan Kelompok Tani dan Gabungan Kelompok Tani. Menteri Pertanian Republik Indonesia.

Hermanto dan Swastika, D. K. S. 2011. Penguatan Kelompok Tani: Langkah Awal Peningkatan Kesejahteran Petani. Pusat Sosial Ekonomi dan Kebijakan Pertanian.

Janudin, 2017. Peranan Kelompok Tani Smber Harapan Dalam Meningkatkan Kesejahteraan Anggota Kelompok Tani Sumber Harapan Desa Tenajar Kidul Kecamatan Kertasemaya Kabupaten Indramayu. Institut Agama Islam Negeri (Iain) Syekh Nurjati Cirebon.

Lestari, M. 2011. Dinamika kelompok dan kemandirian anggota kelompok tani dalam berusahatani Di kecamatan poncowarno kabupaten kebumen propinsi jawa tengah. Universitas Sebelas Maret Surakarta.

Makawekes, N. 2016. Dinamika Kelompok Tani Cempaka Di Kelurahan Meras Kecamatan Bunaken. Universitas Sam Ratulangi Manado.
Nuryanti, S. dan Swastika, D.K.S.E. 2011. Peran Kelompok Tani Dalam Penerapan Teknologi Pertanian. Pusat Sosial Ekonomi dan Kebijakan Pertanian.

Peraturan Menteri Pertanian. Pedoman Pembinaan Kelompok Tani. No.41/Kpts.OT.210/1/1992.

Riyaningtyas, D. P. 2010. Studi Penyelenggaraan Penyuluhan Pertanian di Kecamatan Ngombol Kabupaten Purworejo. Universitas Sebelas Maret Surakarta.

Resicha, P. 2016. Peran Penyluh Pertanian Dalam Pengembangan Kelompok Tani Di Nigari Sungai Pua Kecamatan Sungai Pua Kabupaten Agam. Universitas Andalas Padang.

Revikasari, A. 2010. Peranan Penyuluh Pertanian Dalam Pengembangan Gabungan Kelompok Tani (Gapoktan) di Desa Tempuran Kecamatan Paron Kabupaten Ngawi. Universitas Sebelas Maret Surakarta.

Susanto, H. 2015. Peran Kelompok Tani "Temor Moleran" Dalam Meningkatkan Pendapatan Buruh Tani. Fakultas Ilmu Sosial Dan Ilmu Politik Universitas Jember. 